\title{
Children's oral health in South Africa: Time for action
}

Dental caries is a common, preventable childhood condition. In developed countries, its prevalence is between $1 \%$ and $12 \%$, while in developing countries it may be as high as $70 \% .{ }^{[1]}$ It is caused by localised destruction of tooth enamel, by acid from the bacterial fermentation of dietary carbohydrates. ${ }^{[2]}$ The progression of untreated dental caries leads to marked morbidity, with throbbing pain, abscess formation, inability to eat, sleep disturbances, malaise and reduced quality of life for children being common. ${ }^{[1,2]}$

The condition affects primary teeth more severely than permanent teeth. This is because bacterial mouth flora and host defense systems are still developing in babies and young children. In addition, newly erupted enamel tends to be more susceptible to demineralisation and acid attack from bacterial plaque. ${ }^{[3]}$ Furthermore, the consequences of untreated dental caries may lead to the inability to eat, thereby affecting nutritional intake in young children, lowering the body mass index and resulting in an inability to thrive.

The last national Children's Oral Health Survey undertaken in South Africa (SA) was conducted between 1999 and 2002. It presented an overall picture of the poor state of children's dental health in the country, with the national prevalence of dental caries being around $60 \%$ among 6-year-olds. Furthermore, over $80 \%$ of the caries among children was reported as being untreated. ${ }^{[4]}$

The high levels of untreated disease in the country have been attributed to inadequate human resources and dental facilities in the country. ${ }^{[4,5]}$ This is reflected by a poor oral health professionto-population ratio in terms of dentists, oral hygienists and dental therapists. Gauteng Province has been reported to present with an oral health profession-to-population ratio of 1:6 217, and Limpopo Province has the country's worst ratio of $1: 32967 . .^{[5]}$

Although there has been no other national survey since 2002, a few local surveys suggest an ongoing similar trend in terms of the levels of disease distribution in the country. ${ }^{[6-8]}$ Moreover, the unmet treatment need index seems to have risen, to just over $90 \%$. This means that about $90 \%$ of the dental caries found in SA children goes untreated.

It is therefore clear that SA experiences a high dental caries burden among pre- and primary-school children, which is aggravated by the lack of adequate resources to meet their oral health needs. The National and Gauteng Oral Health Strategies recommend evidencebased policies in terms of addressing and preventing child dental caries; however, implementation of these policies has been met by major challenges. ${ }^{[9,10]}$

During the evaluation of 10 schools-based oral health programmes in the District of Tshwane, the complexities and challenges that oral health providers experience while attempting to implement preventative policy objectives became apparent. The preliminary findings of the analysis revealed that none of the 10 schools evaluated managed to achieve even an acceptable level of adherence (50\%) to policy (Molete et al., 2018).

Challenges that were observed and reported include issues of having to provide school oral health programmes and services without chairside assistance, due to staff shortages. Other factors included defective portable equipment, ill-equipped school facilities, inadequate teacher co-operation and lack of school health-promotion policies addressing sugary snack intake (Molete et al., 2018).

In order to address such challenges, energy and resources need to be geared towards strengthening primary prevention approaches, in order to address the maintenance of child oral health before the onset of dental caries. The most appropriate time for such an approach would be during the postnatal period, when caregivers are navigating the dietary transition between breast, cup and solid feeding. ${ }^{[1,3]}$
A study conducted at two immunisation sites in Johannesburg among children $(N=446)$ between 6 months and 6 years old demonstrated that although the caries level of the children at the sites was below 5\%, the risks that contributed most to early childhood caries included low educational levels of caregivers, poor behavioural patterns of feeding and inadequate oral hygiene practices. ${ }^{[1]}$ Such immunisation sites should therefore be targeted in order to access caregivers and facilitate their oral health awareness around reducing caries risk factors. These settings would additionally create an environment of collaboration among a broader array of healthcare professionals involved in child health.

Oral health programmes at school sites still have a role to play, as the National Health Insurance white paper reported that the majority $(60 \%)$ of healthcare needs among school children stem from oral health problems. ${ }^{[12]}$ Therefore, secondary preventative efforts at school settings need to continue; however, monitoring and evaluation need to occur more regularly, so that areas needing improvement are consistently addressed.

To address the high prevalence of dental disease among children in the midst of limited resources, the approaches of both primary and secondary prevention need to be balanced, in order to ensure that all children are reached, and exposed to oral healthcare. Moreover, considering that oral health is integral to general health and wellbeing, there is opportunity for general health practitioners and other professionals working with children to work collectively with oral health practitioners in strengthening preventative efforts, particularly in remote rural areas, where oral health staff and resources are few. ${ }^{[5,13]}$ This will contribute towards turning the oral health aspirations of the country into reality.

M Molete, M Dent (Community Dentistry)

School of Oral Health Sciences, Faculty of Health Sciences, University of the Witwatersrand, Johannesburg, South Africa

S Afr J Child Health 2018;12(4):133. DOI:10.7196/SAJCH.2018.v12i4.1625

1. Naidoo S, Myburgh N. Nutrition, oral health and the young child. Matern Child Nutr 2007;3(4):312-321. https://doi.org/10.1111/j.1740-8709.2007.00115.x

2. Selwitz RH, Ismail AI, Pitts NB. Dental caries. Lancet 2007;369(9555):51-59. https://doi.org/10.1016/S0140-6736(07)60031-2

3. Seow WK. Biological mechanisms of early childhood caries. Community Dent Oral Epidemiol 1998;26(S1):S8-S27.

4. Van Wyk PJ, van Wyk C. Oral health in South Africa. Int Dent J 2004;54(S6):S373-S377.

5. Thema LK, Singh S. Integrated primary oral health services in South Africa: The role of the PHC nurse in providing oral health examination and education: Open forum. Afr J Prm Health Care Fam Med 2013;1;5(1):1-4. https://doi. org/10.4102/phcfm.v5i1.413

6. Thekiso M, Yengopal V, Rudolph MJ, Bhayat A. Caries status among children in the West Rand District of Gauteng Province, South Africa. S Afr Dent J 2012;67(7):318-320.

7. Reddy M, Singh S. Dental caries status in six-year-old children at health promoting schools in KwaZulu-Natal, South Africa. S Afr Dent J 2015;70(9):396-401.

8. Mothupi KA, Nqcobo CB, Yengopal V. Prevalence of early childhood caries among preschool children in Johannesburg, South Africa. J Dent Child 2016;15;83(2):83-87.

9. National Department of Health. South African National Oral Health Strategy. Pretoria: NDoH, 2010.

10. Singh S, Myburgh NG, Lalloo R. Policy analysis of oral health promotion in South Africa. Glob Health Promot 2010;17(1):16-24. https://doi. org/10.1177/1757975909356631

11. Molete M,Phakela NP. Early childhood caries experience of children accessing selected immunisation facilities in Johannesburg. S Afr Dent J 2018;73(5):330334.

12. National Department of Health. National Health Insurance for South Africa: Towards Universal Health Coverage. Pretoria: NDoH, 2015.

13. Thema KL, Singh S. Oral health service delivery in Limpopo Province. S Afr Dent J 2017;72(7):310-314. https://doi.org/10.17159/2519-0105/2017/ v72no7a3 